\title{
Índice de Qualidade da Educação Fundamental (IQE): proposta para discussão*
}

जロ

Carlos HenriqueAraújo

Frederico Neves Conde

Nildo Luzio

Palavras-chave: avaliação daedu-

cação; taxa deatendimento; ade-

quação idade-série; fluxo escolar;

SistemaNacional deAvaliação da

Educação Básica; Censo Escolar;

IndicadoresEducacionais

\section{Resumo}

Expõeo Índice de Qualidade da Educação (IQE), o qual foi el aborado tomando-seem consideração três indicadores da educação fundamental no País: a taxa de adequação idade-série; a taxa deatendimento, também chamada de freqüência escolar, ea média dos Estados brasil ei ros no Sistema Nacional deAval iação da Educação Básica (Saeb). Portanto, o índice busca refletir três componentes: atendi mento escolar, adequação dos estudantes à sériematriculada e o rendi mento escol ar medido pel a proficiência al cançada na avaliação nacional; busca representar fundamental mente os resul tados da educação mais do que os insumos aportados por meio das políticas educacionais. Os autores acreditam que um bom sistema deensino deve ser aval iado prioritariamente por meio da sua capacidade de atendimento à população em idade escolar, por sua eficiência no fluxo escolar e por sua capacidade deagregar domínios cognitivos aos estudantes.

\section{Introdução}

Os indicadores sociais são medidas criadas com o objetivo de representar o nível de desenvol vimento de uma coletividade ou país. Em geral, os mais utilizados são os de tipo quantitativo, originado de sistemas estatísticos, como o Censo Demográfico e a Pesquisa Nacional por Amostra de Domicílios (Pnad), ambos de responsabilidade do IBGE. Tais sistemas geram indicadores bastante conhecidos, como éo caso da taxa de anal fabetismo da população de 15 anos ou mais de idade.

A primeira classificação dos indicadores retrata sua composição, ou seja, seeleé unidimensional ou multidimensional.
A taxa de analfabetismo éunidimensional, pois reflete apenas um aspecto do segmento educação. Por sua vez, os indicadores multidimensionais são construídos para propiciar uma visão gl obal de um país ou outra agregação geográfica qual quer, como é o caso do Î́ndice de Desenvol vimento Humano (IDH). Elaborado nos anos 70, elereflete três dimensões da vida social: renda, Iongevidade educação. Tornou-seconhecido, principal mente, porquepermitecomparações entre países.

Os indicadores sociais podem, ainda, ser classificados por tema, representando as dimensões habitação, saúde, educação e mercado de trabal ho, entre outras. Em cada uma dessas categorizações existem os

\footnotetext{
* A formulação do IQE, objeto destetexto, foi resultado dediscussões entre os autores. Contou também coma participação do sociólogo Sidnei Volkman, quetrabal hou na Diretoria de Avaliação da Educação Básica doInep atémarço de 2005.
} 
descritivos eos normativos. Os descritivos estão livres de qual quer julgamento acerca da reali dade que representam, pois são puramenteempíricos. Umexemploéadistorção idade-série. A categoria dos normativos exige algum grau de escol ha, de jul gamento, sobre a qual idade da política pública ofere cida. Tomam-secomo exempl os os standards de quali dade deaprendizado escolar.

Outra forma de caracterizar os indicadores écom respeito ao seu objeto. Por esta definição temos os indicadores-insumos, os indicadores-produto e os indicadoresprocesso.

Os indicadores-insumos refletem a quantidade e a qualidade de recursos al ocados para a dimensão social medida. São exemplos, no setor educacional, a quantidade de al unos por professor, o nível de formação dos professores, a quantidade de al unos por sal a de aula, entre outros.

Osindicadores-produto quantificam os resultados queforam al cançados por meio de intervenções de políticas públicas. A proporção de crianças matriculadas nas escol as ea média de aprendizagem dos estudantes são exemplos.

Os indicadores-processo medem a al ocação de recursos para os diversos segmentos depolíticas públicas. Em se tratando de política educacional, temos a quantidade de al unos beneficiados com livros didáticos, o número de al unos que recebem merenda escolar diariamente, entreoutros possíveis exemplos.

Por fim, os indicadores podem ser ana lisados ainda segundo as abordagens de eficiência, eficácia e efetividadedas políticas públicas.

O conceito deeficiência aplicado àava liação da educação representa, por exemplo, a capacidade de ofertar escolas e demais insumos educacionais utilizando-seos recursos de forma racional. Um indicador de eficácia é dado pel a capacidade dos sistemas de ensino para atenderem à população escolar, na faixa etária correspondente a cada nível de ensino considerado, com baixas taxas de repetência e al tas taxas de conclusão. Por sua vez, efetividade referese às medidas de aprendizagem dos componentes curriculares ofertados aos al unos.

Os indicadores são úteis à pesquisa social e ao monitoramento das políticas públicas. Eles serão tanto mais confiáveis e vál idos quanto asseguradas forem a periodicidade e a qualidade da col eta dos dados utilizados em sua formulação.
As definições e classificações dos indicadores até agora apresentadas foram utilizadas na construção do Índice de Qual idade da Educação do Ensino Fundamental (IQE) proposto. Tal índice adquire uma relevância social equival enteà importância da educação para o desenvolvimento do Brasil.

Há fortes evidências empíricas de que mai ores níveis educacionais impactam significativamentena economia, especial mente no aumento de produtividade. Para os indivíduos, mais escolaridade reverte-seem mel hores condições de ingresso no mercado de trabal ho, auferindo mais renda. Existem estudos apontando que uma melhor distribuição do ativo educação pode contribuir para reduzir em até $40 \%$ os níveis de desigual dade no País. Neste sentido, a educação é uma área muito pertinente para a construção de indicadores que retratem de forma efetiva o desenvol vimento educacional do Brasil.

O IQE foi elaborado como indicador de resul tado e de efetividade; el e retrata a capacidade dos sistemas de ensino, em cada Estado da Federação, de atenderem a população da faixa etária obrigatória mantendo os estudantes na escola, para que concluam o ensino fundamental no tempo previsto e na idade correta, associando ainda, a essas variáveis, os níveis de aprendizado al cançados pel os estudantes.

Apesar dos indicadores de insumo e processo serem importantes, optou-se por um índice de resultados, ou seja, uma medida a partir dos níveis de aprendizagem, das taxas defluxo, rendimento eatendimento dos sistemas deensino. Portanto, o índice proposto não incorpora dados de insumos, seja das condições de infra-estrutura, seja do perfil do corpo docente ou mesmo do perfil da gestão. E defato importantegerar informações precisas e confiáveis sobre tais dimensões; no entanto, elas devem ser vistas como condi ção para o al cance da meta central dos sistemas e redes de ensino e das escolas: o aprendizado dos estudantes.

Para um bom funcionamento do sistema, énecessário contar com escolas em boas condições defuncionamento, dotadas deum bom corpo docente egeridas eficientemente, a fim de que os al unos possam agregar domínios cognitivos eincorporar val ores da cidadania e da democracia. Contudo, escolas podem ter bons indicadores de infra-estrutura, docência e gestão e não estar 
atingindo, de forma satisfatória, as metas de formação de seus estudantes. Em resumo, podem não estar atingindo os objetivos centrais da educação formal.

Por essa razão, o IQE foi construído com base em três componentes que espel ham a eficiência, a eqüidade dos sistemas e sua capaci dade de agregar aos estudantes real izações cognitivas nos diversos componentes dos currículos. É um índice que pretende contribuir para o debate e, mesmo, preencher uma lacuna importante para a gestão dos sistemas de ensino no Brasil.

Em se tratando da educação, o Brasil tem, sobretudo desde os anos oitenta, promovido esforços de el aboração de indicadores capazes de descrever a situação educacional. Fazem parte dessas iniciativas a coleta anual do censo escolar e as avaliações dos sistemas de ensino, feitas a cada dois anos pelo Sistema Nacional deAvaliação da Educação Básica (Saeb).

O censo escolar constrói estimativas que permitem aval iar o al cance da educação formal, a eficiência dos sistemas, por meio das taxas de fluxo e rendimento, e, ainda, as condições de infra-estrutura de cada uma das escol as da educação básica.

Por sua vez, o sistema de avaliação, criado em 1990, possi bilita conhecer a eficiência ea eqüi dade dos sistemas de ensino, refl etida em uma medida das realizações cognitivas dos estudantes investigados. Ele é realizado a partir de uma amostra probabilística dealunos das séries de final de cicl os na educação básica - 4a e 8a séries do ensino fundamental e 3a série do ensino médio - aos quais são aplicados testes deLíngua Portuguesa e Matemática. A análise desses instrumentos gera medidas de proficiência representativas estatisticamente para o Brasil, as Regiões e os Estados, estratificada por rede (pública e privada) e dependência administrativa (estadual , municipal, particular e privada).

Até então os indicadores do Censo e do Saeb eram trabal hados de forma isolada; não existia uma medi da agrupando el ementos desses dois sistemas estatísticos. $\mathrm{O}$ IQE é uma proposta deíndice para retratar a qual idade da educação em cada uni dade da Federação.

No próximo tópico, apresenta-se asituação da educação no Brasil por meio de dados censitários e deaval iação. Com isso, pretende-se demonstrar que o IQE deve considerar estas duas dimensões para a sua composição, pois são persistentes os problemas no fluxo educacional edeaprendizagem dos estudantes do ensino fundamental. Essas duas dimensões devem ser objetos principais de políticas públicas e de seu monitoramento, para reverter o quadro bastantedeficitário da educação formal no Brasil.

\section{Situação atual da educação básica no Brasil}

\section{Dados de fluxo, rendimento e acesso}

Consi derando-se o período de 1990 a 2004, houveal guns avanços na educação no Brasil, como a queda na taxa deanal fabetismo das pessoas de 15 anos ou mais de idade, que em 1992 era de 17,2\% e, em 2003, baixou para $11,6 \%$. Outro dado importante foi o aumento da média de anos de estudo da população adulta, que em 1993 era de 6,02 e, em 2003, passou a ser de 7,26. ${ }^{1} \mathrm{De}$ 1995 a 2001, houve mel horias na média de anos de estudo em todas as regiões.

A prioridade nacional das políticas públicas em educação tendo em vista o acesso das crianças de 7 a 14 anos à escola garantiu uma mel hora na taxa de freqüência: de 80,9\% em 1980 para 97,2\% em 2003, conformea Pesquisa Nacional por Amostra deDomicílios (Pnad), do IBGE.

Esses e outros dados evidenciaram avanços no período de 1990 a 2004; no entanto, o sistema educacional brasileiro ainda convivecom grandes egraves problemas. Em relação à alfabetização, por exemplo, perduram fortes desi gual dades entre as regiões do País. Segundo o Censo Demográfico de 2000 , o Sudestetinha $8,1 \%$ de anal fabetos (pessoas incapazes de ler eescrever um enunciado simples relacionado com sua vida diária) com 15 anos de idade, e o Nordeste, $26,2 \%$.

A taxa de atendimento escolar na faixa de 7 a 14 anos está marcada por diferenças entre as regiões: em 2003, no Norte, era de $95,9 \%$, e no Nordeste, de $96 \%$ - portanto, abaixo da taxa nacional, que era de $97,2 \%$-, enquanto no Sul eno Sudeste ela se situava, respectivamente, em 98\% e 98,1\%.

As desigual dades de acesso e de indicadores demográficos explicam-se, em parte, pel os graves problemas de fluxo educacional. Para seter uma idéia de como o fluxo e o rendimento do sistema escolar

\footnotetext{
Segundo a Pesquisa Naciona por Amostra de Domicílios (Pnad/IBGE).
} 
precisam deatenção específica, basta citar que a distorção idade-série no ensino fundamental afeta, hoje, metade dos estudantes matriculados.

Consi derando-se as oito séries do ensino fundamental, $33 \%$ dos al unos repetiam uma série a cada ano. Nesse nível de ensino, os al unos ficavam, em média, nove anos, e os que o concluíam levavam, em média, 11 anos. A grande mai oria dos alunos tinha pel o menos uma repetência, mas insistia em ficar na escola, só saindo após vários anos, por não conseguir progredir.

Astaxas de rendimento têm fortes conseqüências para as distorções em todo o fluxo escolar, gerando um tempo maior de permanência dos estudantes nos sistemas de ensino. Por exemplo, entre 1998 e 2001, o tempo médio de permanência no ensino fundamental foi de dez anos, quando o aluno deveria levar oito anos para concluir essa etapa.

Os prejuízos decorrentes do atraso escolar são enormes, afetando as crianças e jovens que não conseguem concl uir o ensino fundamental ou o concluem após sucessivas repetências. Em termos gerais, são prejuízos para a sociedade, já que parcela significativa de seus recursos está sendo desperdiçada. Para o estudante em situação de atraso escolar, os prejuízos são duplos: sua auto-imagem é depreciada e seu desempenho escolar é abaixo da média, conforme demonstrado pelos sucessivos ciclos do Saeb.

Concl uir o ensino fundamental éuma barreira para a mai oria dos ingressantes. Estima-se que, em 2001, de cada 100 al unos quehaviam ingressado na primeira sé rie, cerca de 62,3 conseguiramtermi nar esse nível de escolarização, levando em média onze anos. Todos os dados atéagora arrola dos evidenciam fal has de eficiência nos sistemas educacionais em todo o Brasil.

A pesar da taxa média esperada de conclusão dos primeiros oito anos deescolaridadeter crescido de 51,9\% em 1995 para 65,8\% em 1997, não mais quea metade dos al unos matriculados concluirá o ensino fundamental, mesmo comatraso escolar. Como sepode notar, a mediana das idades de concl usão do nível fundamental permaneceu constanteem 15 anos, já na rede privada a mediana correspondeu sempreao ideal, 14 anos.

Os patamares de reprovação e repetênciaai nda são muito al tose, também, mais al tos nas duas séries iniciais. Como conseqüência dessa grande repetência, muitos al unos acabam sendo "expulsos" da escola e não concluem a primeira etapa de escolarização. Esse processo atinge com muito mais intensidadeas populações mais pobres e, especialmente, os pobres de cor negra.

Pequenas mel horias no fluxo do ensino fundamental têm repercutido no aumento da demanda por vagas no ensino médio; esse fato pode ser confirmado pel o crescimento do número de matrículas. No período entre 1999 e2003, as matrículas iniciais no ensino médio expandiram-se em todos os anos, passando de 7.769.199 em 1999 para 9.072.942 em 2003, variação correspondente a $16,8 \%$.

De forma conseqüente ao aumento no ingresso de estudantes na escola de nível médio, este conheceu um crescimento no número de concluintes da ordem de $22,7 \%$, passando de 1.535.943 em 1998 para 1.884.874 em 2002. Contudo, tais avanços convivem com problemas de eficiência das redes de ensino que atendem ao nível mé dio. Um dos mais graves é a distorção idade-série, que é de 49,3\% (dados de 2003). As precárias taxas de rendimento se refletem no tempo médio esperado para conclusão: era de 4 anos em 1995, caiu para 3,6 anos em 1998 e subiu para 3,7 anos em 2001. De 1999 para 2000, a idade mediana de conclusão diminuiu de 19 para 18 anos de idade. O ideal seria que, tendo concluído a 8a série aos 14 anos, o al uno concluísseo ensino médio aos 17. Entre 1999 e2003, a taxa de distorção idade-série diminuiu de 54,8 para 49,3 . A pesar dos números mostrarem al gumas mel horias, a eficiência do sistema, medida pel o fluxo escolar, ébaixa.

Se há problemas no fluxo educacional do ensino médio, também existem deficiências em outras áreas da política educacional, constituindo-se diversas barrei ras para atender à demanda. Um problema sério éa fal ta de docentes, como apontado pel o $\mathrm{Mi}$ nistério da Educação. Estima-se um déficit de 250 mil professores em todo o Brasil, principal mente nas áreas de Matemática, Física, Química eBiologia.

Os dados apresentados acerca do fluxo educacional da educação básica, no Brasil, compõem um quadro com sérios problemas; mostram que ainda há muito a fazer para que os sistemas de ensino atinjam um padrão de eficiência aceitável. Na próxima seção será discutida a eficiência dos sistemas de ensino a partir dos resultados deaprendizagem dos al unos. 


\section{Dados de qualidade do aprendizado}

As referências para a discussão aqui implementada são os dados produzidos a partir do Sistema Nacional deAvaliação da Educação Básica (Saeb). O sistema foi criado em 1990 e desde 1995 é real izado a cada dois anos. É um model o de aval iação que tem doisfocos: medidas cognitivas emedidas contextuais. A informação sobre o nível de desenvol vimento decompetênciase habilidades dos alunos é construída por meio da aplicação detestes nos componentes curriculares de interesse da aval iação, mais comumentemediantemedidas dedesempenho em Língua Portuguesa e Matemática.

O desempenho dos al unos nos testes éanal isado, em termos psicométricos, por meio da Teoria de Resposta ao Item (TRI). Esta teoria desenvolveu-se a partir de model os matemáticos que permitem comparar os desempenhos dos al unos, mesmo que sejam de amostras diferentes e tenham feito testes diferentes. Desta forma, tem sido possível, desde 1995, monitorar os sistemas de ensino pela observação do desempenho dos estudantes nos testes a cada ciclo do Saeb. As metodologias de análise permitem investigar como se comporta o desempenho diante de um referente mínimo denominado de Média Mínima Satisfatória (MMS) e averiguar o nível de eqüidade entre os sistemas de ensino, seja comparando as regi ões, seja comparando Estados da Federação, seja comparando, dentro do mesmo Estado, as redes de ensino.

Para que se façam comparações pertinentes e para quese investiguem os fatores de contexto correlacionados ao desempenho escolar, o Saeb constrói medidas contextuais. Para tanto, a cada ciclo são aplicados questionários aos estudantes das turmas amostradas, aos professores destas turmas, aos diretores das escol as das quais fazem parte as turmas e, ainda, um outro destinado a coletar informações sobre as condições deinfra-estrutura das escol as.

No ciclo deaval iação do Saeb em 2003 foram aplicados testes de Língua Portuguesa eMatemática construídos a partir deuma matriz deespecificações. Para a Língua Portuguesa, a matriz rel aciona habilidades que orientam a el aboração dos itens de testes destinados a medir o desempenho dos al unos emleitura, isto é, sua competência para lidar com textos de gêneros variados, por meio da local ização deinformações explícitas, fazer inferências, identificar o tema do texto e comparar textos que tratam do mesmo assunto, entre outras.

O gráfico a seguir mostra as médias de proficiência, em Língua Portuguesa, dos estudantes das três séries investigadas. A leitura do gráfico exige saber queas médias de proficiência, original mente padronizadas, são convertidas em uma escal a que varia de $0 \mathrm{a}$ 500 pontos, e, ainda, ter em mente que as proficiências dos al unos das três séries são estimadas numa mesma escal a. Por último, para uma mel hor análise ecompreensão do gráfico, é pertinente comparar a média estimada coma MMS, ${ }^{2}$ queaponta um nível de proficiênciasatisfatório, conformea série.

O gráfico com as médias de proficiência das três séries em leitura mostra que, em termos gerais, o desempenho dos estudantes está abaixo do mínimo. A distância entre a média auferida e a MMS revela o principal problema da educação em todo o Brasil: a bai xa qual idade do ensi no-aprendizagem.

\section{Médias de proficiência em leitura - 4a e 8a séries do Ensino Fundamental e 3a série do Ensino Médio - Brasil - 2003}

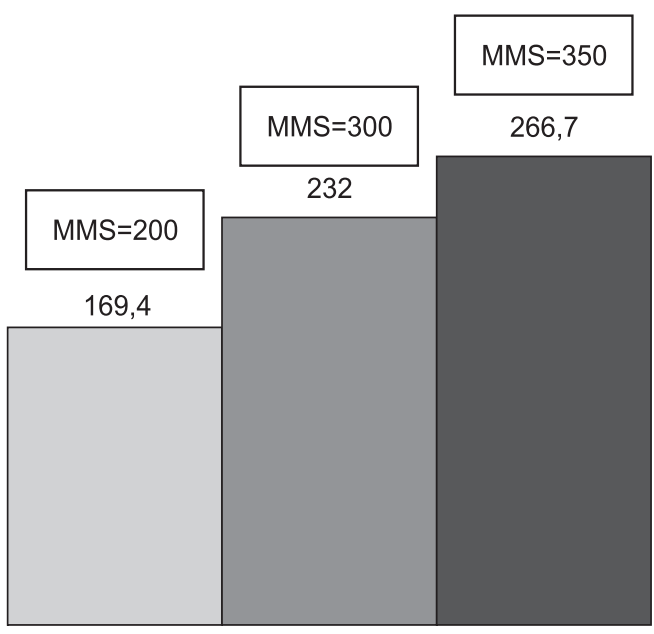

$\square 4^{\mathrm{a}}$ série/EF $\square 8^{\mathrm{a}}$ série/EF $\square 3^{\mathrm{a}}$ série/EM Fonte: MEC/INEP/Saeb

A avaliação de Matemática, como a de Língua Portuguesa, é feita a partir de uma matriz de especificações, relacionando as competências de lidar com os números e operações, espaço e forma, tratamento da informação eál gebra.

\footnotetext{
AMMSindicaumpontoemque o estudantedesenvolveu habilidades mais condizentes com a sériequeestáfreqüentando. Portanto, amédiamínimareve laumatrajetóriaescolarmelhor, mais consistente do queéem patamares abaixo do mínimo, evidenciando umaprendizado superior eadequadoaosobjetivos cognitivos do currículo do ensino fundamental.
} 
O próximo gráfico mostra as médias de proficiência em Matemática, nas três séries avaliadas. O aprendizado de Matemática está aquém do mínimo em todas as séries aval iadas. A questão central éa fal ta de eficiência, assim como no caso de Língua Portuguesa.

\section{Médias de proficiência em Matemática na 4a e 8a séries do Ensino Fundamental e na 3ạ série do Ensino Médio - Brasil - 2003}

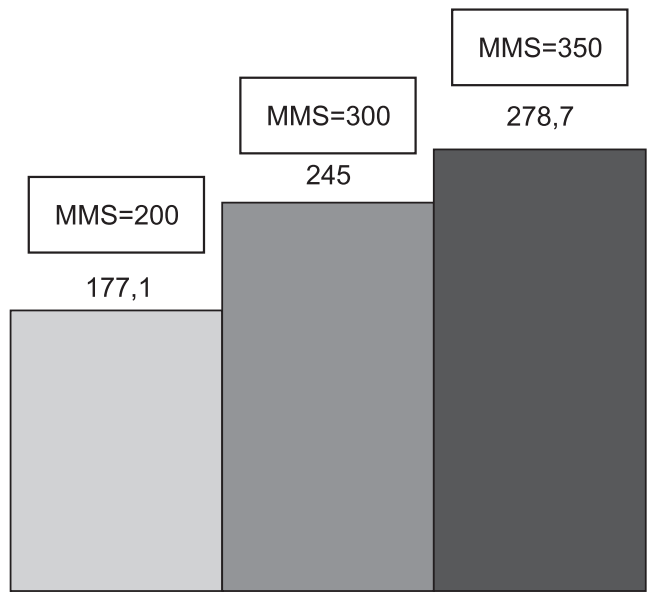

$\square 4^{\mathrm{a}}$ série/EF $\square 8^{\mathrm{a}}$ série/EF $\square 3^{\mathrm{a}}$ série/EM Fonte: MEC/NEP/Saeb

\section{Índice de Qualidade da Educação (IQE)}

A té então foi possível demonstrar os problemas correlacionados com o baixo desempenho dos sistemas deensino no Brasil. Há problemas defluxo escolar, insuficiência de atendimento e de aprendizagem. O IQE foi construído com basenos três principais indicadores que espel ham a eficiência, a eqüidade e a capacidade dos sistemas para agregar aos estudantes realizações cognitivas nos diversos componentes dos currículos.

O IQE agrega o Componente Desempe nho Educacional (CDE), o de Adequação Idade-Série (Cais) e o de Atendimento Escolar (CAE). A escol ha destas três medidas, com certeza, refl ete uma val orização de algumas dimensões, atribuindo-lhes um peso mais intenso do que para outras.

A escol ha destes três componentes foi baseada no pressuposto de que um sistema de ensino eficiente requer escol as dotadas de boas condições de infra-estrutura, um quadro de professores bem formados e capacitados, diretores eficientes e com perfil deliderança. Buscar constituir a educação com estas características deve ser, sem dúvida, a preocupação central dos governos. Ademais, éimportantecontar com um bom sistema de ensino para quesejam dimi nuídas as desigual dades, sejam el as oriundas da região onde mora o estudante, de seu nível socioeconômico, de sua cor ou da escola onde estuda.

Para que se atinja uma boa educação, vários são os fatores a serem consi derados; o nível de prioridade atribuído pela sociedade e pel os governos ao setor é um deles, sendo também importante o montante de investimento que o País, os Estados e os municípios destinam à educação. Do ponto de vista gerencial, é necessário contar com indicadores que possam mostrar, de forma clara, o desempenho do sistema.

O índice de qual idade da educação foi elaborado a partir da escol ha de três dimensões, a saber: os dados de aprendizado do Saeb, de atendimento (taxa defrequência) e de distorção idade-série, queéuma medida síntese do fluxo educacional. Estas três dimensões evidenciam o nível de aprendizagem dos estudantes, a capacidade deatendimento dos sistemas à população em idade escolar para cadanível deensino e, ainda, se os sistemas não estão sendo afetados por muita retenção, causada por altas taxas de repetência, de reprovação ou deabandono.

O Componente de Adequação IdadeSérie (Cais) mostra o percentual deestudantes matriculados na série consi derada ideal para sua idade; esse indicador podeser calculado por idade ou por faixa, de 7 a 14 anos, considerada ideal para o ensino fundamental. Nos países de mais alto desenvolvimento, a adequação idade-série está sempre acima de $90 \%$. No Brasil, observase que ainda temos altos percentuais de distorção, refl etindo diversos problemas de fluxo educacional, tais como al tas taxas de reprovação, abandono eingresso tardio na escola.

A reprovação e o abandono, por sua vez, incidem de forma muito mais acentuada nas escolas públicas freqüentadas por estudantes de mais baixo capital socioeconômico. Combater a distorção idade-série, garantindo um ensino de qualidade, representa inclusão educacional esocial. Nesse sentido, incluir tal indicador na composição do IQE faz-sefundamental, uma 
vez que deve ser objetivo central dos sistemas deensi no mel horar os níveis deaprendizagem dos estudantes. Mas tal meta não podeser atendida excluindo-seestudantes.

O ComponentedeAtendimento EscoIar (CAE) refleteo objetivo degarantir o acesso da totalidade da população às escolas. A inclusão deste indicador éfundamental para não se deixar em segundo plano os esforços de universalização da educação básica; em outras palavras, para que cada Estado da Federação tenha um bom IQE, ele devese preocupar em aumentar suataxa de atendimento, garantindo pelo menos uma equi paração coma taxa nacional.

O Componente de Desempenho Educacional (CDE), principal dimensão do índice, espelha, por meio dos resultados de proficiência dos estudantes em Língua Portuguesa e Matemática no Saeb, a qualidade da educação. A avaliação apresenta os resultados de proficiência dos estudantes em uma escal a de Matemática e outra de Língua Portuguesa, ambas variando de 0 a 500 pontos. Para cada disciplina, os desempenhos dos al unos de $4^{\mathrm{a}}$ e $8^{\mathrm{a}}$ séries do ensino fundamental e de $3^{a}$ série do ensino médio são apresentados na mesma escala, fornecendo uma clara idéia do avanço na formação das competências no decorrer da trajetória escolar.

O CDE é calculado com base na distância de resultados médios de proficiência deal unos de escolas públicas diantedo patamar mínimo para cada nível de escolarização, o MMS. ${ }^{3}$ Em Língua Portuguesa (LP), na 4a série, o mínimo aceitável é de 200 pontos $^{4}$ e, na 8a série, o escore deve ser de $300 .^{5}$ Em Matemática, o mínimo para a 4ª série étambém de $200^{6} \mathrm{e}$, para a 8a série, espera-se que os estudantes tenham alcançado 300 na escala de proficiência do Saeb. ${ }^{7}$

Na composição do CDE, não se comparam, entre si, resultados de proficiência dos estudantes em Língua Portuguesa eMatemática, estratégi a que seria tecnicamente inviável, porqueas escal as têm métricas diferentes. No entanto, incorporar a magnitude da distância das médias ao mínimo é aceitável nas duas disciplinas para a criação do componente, retratando as duas áreas de competências. Esta estratégia é perfeitamentejustificável.

O CDE para o ensino fundamental podeser cal culado, para os diversos estratos amostrais do Saeb, de acordo com a seguinteexpressão matemática:

$$
C D E_{E F}=\frac{3 M_{4}+3 P_{4}+2 M_{8}+2 P_{8}}{24},
$$

em que $M_{4}$ e $M_{8}$ são as médias dos estudantes em Matemática para a $4^{\mathrm{a}}$ e $8^{\mathrm{a}}$ séries, respectivamente; $\mathrm{P}_{4}$ e $\mathrm{P}_{8}$, as médias dos estudantes em Língua Portuguesa para a $4^{\mathrm{a}}$ e $8^{\mathrm{a}}$ séries, respectivamente. Verifica-seque, caso as médias de $4^{\mathrm{a}}$ série sejam 200 e as de $8^{a}$ sejam 300, ou seja, os val ores mínimos aceitáveis, o CDE terá val or de 100. Ressal te-se que esteval or pode, teoricamente, ultrapassar 100, caso ocorram mel horias de média de desempenho indo além do mínimo definido.

O IQE é cal culado consi derando, então, os resultados dos três componentes. Decidiu-se por atribuir pesos diferentes para cada um deles, de forma a refletir a realidade educacional atual diante de uma situação ideal. Assim, um peso mai or foi atribuído para as situações mais distantes do aceitável. O CAE mereceu peso 1, visto que o acesso ao ensi no fundamental está praticamente assegurado. O Cais recebeu peso 2, pois o fluxo educacional (repetência e abandono) vem se mostrando ainda um problema muito grave e que mereceatenção especial pel as políticas educaci onais. Ainda persi stem al tas taxas de distorção idade-série. O CDE, por sua vez, mereceu peso 4, por refletir o mais grave problema educacional atual, o da qualidade do ensino eaprendizado, conforme evidenciado pelos baixos níveis de proficiência dos estudantes nos componentes curriculares avaliados.

A combinação dos componentes reforça quenão basta inserir as crianças na escola, mas é preciso ensiná-las bem, com um fluxo educacional não-excludente. Assim, o IQE do ensino fundamental é cal culado por meio da seguintefórmula:

$I Q E_{E F}=\frac{4 \times\left(C D E_{E F}\right)+2\left(C A I S_{E F}\right)+\left(C A_{E F}\right)}{7}$,

em que:

$\mathrm{CDE}_{\mathrm{EF}}=$ Componente de Desempenho do Ensino Fundamental (EF).

$\mathrm{CAIS}_{\mathrm{EF}}=$ Componente de Adequação Idade-Série do EF.

$\mathrm{CAE}_{\mathrm{EF}}=$ Componente deAtendimento Escolar.
Oquesignificao mínimo para cadasérie?O mínimoindicaum patamar em que os estudantes desenvolveram, nasáreas avaliadas, habilidades cognitivas satisfatórias para o tempo de escolarização pelo qual passaram. O mínimo satisfatório evidencia uma trajetória escolar bem realizada; significa queo estudanteconsolidou compe tências queo permitem continuar os estudoscom bomaproveitamento ou sedediqueaalgumaáreadeatividadeprofissional comautonomia deaprendizagem.

4 Estarnessepatamar significa, re sumidamente, queo estudante desenvolveu acontento as habiidadespróprias deumleitorque compreendetextos de gêneros variados, tais como: anedotas, pequenas narrativas, fábulas, textos de caráter informativo histórias em quadrinhos. E capaz delocalizarinformaçõesexplícitas, identificar as persona gens dos textos, distinguir fato deopinião, compreender as re lacões decausaeconseqüência bem como efeitos desentido a partir da pontuação edeoutras formas denotações.

Demaneirageral, osalunosque seencontramnonível 300 reve lam-secapazes deapreender aspectos da construção coesiva dostextose dessaforma, asse gurar a continuidade do texto pelo recurso das substituições pronominais ou pelas relações dedependênciaentretermosque expressam causa econseqüência; saber por queo autor inseriu notextoumdiálogoou umenunciado opinativo; maisainda, re conhecer os efeitos expressivos do uso derecursos gráficos em textos poéticos; encontrar sentido parao uso degírias edeexpressões col oquiais einterpre tar padrões sintáticos menos usuais, istoé, mais distantes do padrão elementar da frasesim plesedaordem direta.

6 Estudantesquealcançamamé dia mínima satisfatória possuemdomínio completo do siste madenumeração decimal, efe tuam subtrações mais complexas, fazem multiplicações por números dedoisal garismosedivisõesexatas por numeros deum algarismo. Resolvemproblemas simples envolvendo essas ope rações e resolvem problemas usando dados apresentadosem gráficos ou tabelas simples.

Os alunos com proficiência satisfatória(300 pontos) paraa aa sériedoensino fundamental reconhecem um quadrado fora da posição usual eidentificam elementos defiguras tridimensionais. Avaliam distâncias horizontaiseverticaisemumcroqui, usando uma escal a gráfica dada por umamal haquadriculada, ereconhecemo paralelismo deretas. São capazes decontar 


\section{A situação da educação no Brasil medida a partir do IQE}

A Tabela 1 apresenta as informações de base utilizadas no cál culo do IQE para cada um dos Estados brasileiros. A ordenação do quadro está feita na coluna do índice, do mai or para o menor valor.
Umaanálisedecadaum dos componentes ajuda a tornar mais evidente quais são as dimensões quemais fortementecontribuem para as desigual dades educacionais que afetam o País; mostram quais aspectos - sejam os rel ati vos ao acesso, ao fluxo ou à aprendizagem - necessitam ser alvo de mai or preocupação das políticas públicas educacionais.

Tabela 1 - Índice de Qualidade e Equidade no Ensino Fundamental

\begin{tabular}{|c|c|c|c|c|c|c|c|c|}
\hline \multirow{2}{*}{ UF } & \multicolumn{4}{|c|}{ Médias de Desempenho } & \multirow{2}{*}{ CDE } & \multirow{2}{*}{ CAIS } & \multirow{2}{*}{ CAE } & \multirow{2}{*}{ IQE } \\
\hline & LP04 & LP08 & MA04 & MA08 & & & & \\
\hline Paraná & 189,0 & 233,1 & 200,1 & 252,1 & 89,1 & 76,4 & 97,7 & 86,7 \\
\hline São Paulo & 176,5 & 228,7 & 181,7 & 243,8 & 84,2 & 85,8 & 98,5 & 86,6 \\
\hline Rio Grande do Sul & 184,8 & 245,6 & 193,3 & 260,7 & 89,5 & 74,5 & 97,8 & 86,3 \\
\hline Santa Catarina & 178,9 & 236,8 & 185,7 & 249,9 & 86,1 & 79,8 & 98,9 & 86,1 \\
\hline Minas Gerais & 178,1 & 224,9 & 193,2 & 244,6 & 85,5 & 73,3 & 97,9 & 83,8 \\
\hline Di strito Federal & 184,0 & 228,5 & 191,0 & 244,8 & 86,3 & 69,2 & 98,0 & 83,0 \\
\hline Roraima & 156,3 & 234,0 & 162,4 & 239,4 & 79,3 & 71,3 & 96,1 & 79,4 \\
\hline Espírito Santo & 165,7 & 220,4 & 174,6 & 231,7 & 80,2 & 67,9 & 97,0 & 79,0 \\
\hline Mato Grosso do Sul & 165,2 & 232,2 & 171,0 & 244,0 & 81,7 & 64,4 & 97,5 & 79,0 \\
\hline Goiás & 170,7 & 232,7 & 177,9 & 238,0 & 82,8 & 57,5 & 97,7 & 77,6 \\
\hline Rondônia & 157,1 & 218,5 & 165,9 & 229,4 & 77,7 & 67,0 & 95,6 & 77,1 \\
\hline Mato Grosso & 158,9 & 220,2 & 170,6 & 234,2 & 79,1 & 62,1 & 94,8 & 76,4 \\
\hline Tocantins & 164,8 & 218,6 & 171,0 & 220,4 & 78,6 & 57,7 & 96,3 & 75,1 \\
\hline Amapá & 154,2 & 226,0 & 160,0 & 224,8 & 76,8 & 59,9 & 95,9 & 74,7 \\
\hline Rio de Janeiro & 168,5 & 229,1 & 174,7 & 229,6 & 81,1 & 50,0 & 97,9 & 74,5 \\
\hline Maranhão & 159,8 & 218,3 & 163,4 & 222,9 & 77,2 & $\mathbf{5 8 , 0}$ & 95,2 & 74,2 \\
\hline Acre & 155,5 & 223,1 & 155,7 & 224,0 & 76,2 & 58,3 & 98,1 & 74,2 \\
\hline Ceará & 163,5 & 219,2 & 164,1 & 220,7 & 77,6 & 52,6 & 96,2 & 73,0 \\
\hline Pará & 158,4 & 228,9 & 164,1 & 231,2 & 78,7 & 47,3 & 95,7 & 72,1 \\
\hline Piauí & 152,6 & 216,8 & 155,4 & 226,0 & 75,4 & 51,9 & 97,9 & 71,9 \\
\hline Rio Grande do Norte & 144,3 & 214,3 & 151,8 & 225,6 & 73,7 & 54,2 & 96,9 & 71,4 \\
\hline Bahia & 156,2 & 223,5 & 166,8 & 229,3 & 78,1 & 43,5 & 95,6 & 70,7 \\
\hline Amazonas & 157,3 & 218,4 & 163,7 & 223,5 & 76,9 & 44,2 & 95,3 & 70,2 \\
\hline Sergipe & 156,1 & 215,5 & 161,7 & 224,4 & 76,4 & 42,8 & 97,5 & 69,7 \\
\hline Paraíba & 155,3 & 215,0 & 167,5 & 218,6 & 76,5 & 42,5 & 97,4 & 69,7 \\
\hline Pernambuco & 153,6 & 214,6 & 159,0 & 221,7 & 75,4 & 40,1 & 95,8 & 68,1 \\
\hline Alagoas & 154,8 & 217,9 & 161,5 & 225,9 & 76,5 & 38,5 & 93,7 & 68,0 \\
\hline
\end{tabular}

Fonte: MEC/Inep/Daeb

blocos em um empilhamento representado graficamenteesa bemque, emfigurasobtidas por ampliação ou redução, osângulos não seal teram. Reconhe cem, ainda, o significado da palavra perímetro efazem estimativas baseadas em informa ções contidas em figuras. Efetuam operações com horas e minutos, fazendo a redução de minutosemhoras.
Observando as colunas das médias de cada Estado na avaliação do Saeb de 2003, vê-se que nenhum deles atingiu o mínimo satisfatório. A busca por mel horias nos níveis deaprendizagem dos estudantesé, portanto, necessária em todos os Estados brasileiros. Mesmo os que são mais ricos têm queavançar emtermos dequalidadedaeducação, como são os casos de São Paulo e Rio Grande do Sul. Em todos os Estados, portanto, o problema de eficiência está pre sente. Aliando-se à falta de qualidade, tem-se a bai xa eqüidade entre as unidades da Federação.

Com rel ação ao Componente de Desempenho Educacional, podem-se agrupar os 26 Estados e o Distrito Federal em dois grandes grupos. O primeiro, reunindo aqueles Estados que têm um CDE acima de 80. São el es: Paraná, São Paulo, Rio Grande do Sul, Santa Catarina, Minas Gerais, Distrito Federal , Espírito Santo, Mato Grosso do Sul, Goiás e Rio de Janeiro. 
O segundo grupo é composto pelos Estados com IQE entre 73 e 79,9. Nessa situação encontram-se Acre, Alagoas, Amazonas, Amapá, Bahia, Ceará, Maranhão, Mato Grosso, Pará, Paraíba, Pernambuco, Piauí, Rio Grande do Norte, Roraima, Rondônia, Sergipee Tocantins.

Em se tratando do Componente de Atendimento Escolar, o indicador nacional, conformea Pnad ${ }^{8} 2003$, mostra que, no Brasil, 0 atendimento à faixa etária de 7 a 14 anos atingiu $97,2 \%$ da população potencial. Nestecomponentetambém há uma forte heterogeneidade entre os Estados.

Em rel ação à média nacional, existem 12 Estados com uma proporção de atendimento acima de 97,2\%. São eles: Paraná, São Paulo, Rio de Janeiro, Rio Grande do Sul, Santa Catarina, Minas Gerais, Distrito Federal, Goiás, Acre, Piauí, Sergi pe, Paraíba e Mato Grosso do Sul.

Os Estados com proporção de atendimento abaixo da nacional somam 15. São eles: Roraima, Espírito Santo, Rondônia, Goiás, Mato Grosso, Tocantins, Amapá, Maranhão, Ceará, Pará, Rio Grande do Norte, Bahia, Amazonas, Pernambuco eA lagoas. Para estas unidades da Federação, portanto, a mel horia do seu IQE implica, também, ampliar o atendimento na faixa etária.

Também, no Componentede Adequação I dade-Série (Cais) constatam-se fortes diferenças quando se compara a situação dos Estados. Com rel ação a este quesito, o padrão internacional, considerando-se os países ricos, éacima de $90 \%$ de estudantes na série correta para sua idade. A situação brasileira está muito distantedeste patamar, sendo que, pelo indicador nacional, existem perto de $50 \%$ das crianças freqüentando o ensino fundamental com a idade acima da ideal para a série em que estão matriculadas.

A heterogeneidade em termos de adequação idade-série é mais al ta do que nos demais componentes. Pode-sefal ar em seis grupos de Estados: o primeiro, com São Paulo, o único Estado com taxa de adequação acima de $80 \%$; o segundo é composto por cinco Estados, comtaxas acima de $70 \%$ e abaixo de 80\% - Paraná, Rio Grande do Sul, Santa Catarina, Minas Gerais, Roraima; o terceiro reúne quatro Estados com adequação variando entre $60 \%$ e 70\% - Espírito Santo, Mato Grosso do Sul, Rondônia e Mato Grosso; o quarto abriga os Estados de Tocantins, Amapá, Rio de Janeiro, Maranhão, Acre, Ceará e Rio Grande do
Norte, cuja adequação varia entre $50 \%$ e $60 \%$; o quinto compreende a faixa que varia de $40 \%$ a 50\% de adequação na faixa etária obrigatória e é composto por Pará, Bahia, Amazonas, Sergipe, Paraí ba ePernambuco; final mente, um sexto grupo abrangendo ape nas o Estado de Alagoas, cuja taxa de ade quação está abaix xo de $40 \%$.

A análise da variabilidade dos escores em cada um dos componentes permite vislumbrar que todos os Estados, inclusive os mais ricos, têm que mel horar seu índice de qualidade por meio de ações que incrementem todos os componentes - todos eles estão distantes do i deal. A análise detaIhada por componentes permitevislumbrar em qual dimensão da política educacional os esforços são mai s urgentes e necessários.

\section{Conclusão}

A idéia princi pal quemotivou a proposição do IQE foi, principalmente, incentivar o debate sobreas questões mai s cruciais da qual idade da educação no Brasil. É importante que tal debateseja franco e aberto, pois, de maneira geral, os assuntos de interesse público, quando tratados de maneira dogmática, não contribuem para o avanço do nível de conhecimento acumulado nas áreas, e, mesmo, para a qual idade das intervenções das políticas públicas.

A motivação para se pensar o indicador foi baseada na evidência da importância da educação para o desenvol vi mento do País e na di mi nui ção das desi gual dades sociais pela distribuição mais igualitária da escolarização.

A motivação é também orientada por uma postura técnica que atribui importância à utilização de informações de qual idade na ação governamental, apoiando as decisões eas execuções. Por outras palavras, é preciso planejar, fixar metas, persegui-las e avaliar seos objetivos foram al cançados. Para tanto, é de extrema utilidade saber em quais dimensões da real idade se deveintervir com maior ênfase.

Sabe-se que a racional idade técnica é crucial, porém ela não permi teobter um total controle da real idade enem prever todas as conseqüências das ações; contudo, negar a importância dos dados e dos indicadores no campo das políticas públicas éuma postura conservadora. Neste sentido, as informações devem servir a toda a sociedade democrática e permitir ao cidadão maior
Pesquisa Nacional por Amostra deDomicílios-IBGE, 2003. 
conhecimento sobreaquilo quelheéoferecido por meio dos serviços públicos.

Umindicador como oIQE podeatémesmo servir como bússola para políticas de responsabilização orientadas em favor de mel horias de todo o setor educacional e decada uma desuas escolas. É evidenteque políticas deresponsabilização quegerem maior desigual dade entreescolas, redes ou mesmo Estados não interessam. Elas devem servir, fundamental mente, para el evar a qual idadeea eqüidade dos mais frágeis do sistema.

\section{Referências bibliográficas}

ARAÚJO, Carlos Henrique. Exclusão educacional. Diário de São Paulo, São Paulo, 11 dez. 2003. 2003.

Retrato eevolução da qual idade do ensino. Jornal do Brasil, Rio de Janeiro, 3 jul.

ARAÚJO, Carlos Henrique; CASTRO, Ubiratã. Desi gual dade racial edesempenho escolar. O Globo, Rio de Janeiro, 16 set. 2003.

ARAÚJO, Carlos Henrique; LUZIO, Nildo. Fracassados aos sete anos? Jornal de Brasília, Brasília, 7 fev. 2005. 2004. . Ensino da Matemática na Educação Básica. Gazeta do Povo, Curitiba, 11 nov. 2004 Alfabetização: uma questão a ser resolvida. Jornal de Brasília, Brasília, 26 out. Educação e desigual dades regionais? Jornal de Brasília, Brasília, 1 set. 2004. . Educação: quantidadee qualidade. Jornal do Brasil, Rio de Janei ro, 16 ago. 2004. . Leitura na educação básica. O Estado de Minas, Belo Horizonte, 25 jun. 2004. Longe do mínimo de qualidade. Jornal de Brasília, Brasília, 16 abr. 2004.

ARAÚJO, Carlos Henrique; PACHECO, Eliezer. Avaliação da educação básica. Brasília: <htpp.www.inep.gov.br/artigos> Acessado em: 18 jan. 2005.

. Boa escola: evidências do Saeb. Disponível em: < htpp.www.inep.gov.br/artigos> Acessado em: 17 jun. 2004.

INSTITUTO BRASILEIRO DE GEOGRAFIA E ESTATIÍSTICA. Síntese de indicadores sociais. Rio deJaneiro, 2003.

INSTITUTO NACIONAL DE ESTUDOS E PESQUISAS EDUCACIONAIS ANÍSIO TEIXEIRA (Inep) Resultados do Saeb 2003. Brasília, junho de 2004. 2004. Análise qualitativa dos Itens de Matemática do Saeb 2003. Brasília, junho de de2004.

Análise qualitativa dos Itens de Língua Portuguesa do Saeb 2003. Brasília, junho Indicadores Educacionais. Disponível em: <www.inep.gov.br/edutabrasil> 
Carlos HenriqueA raújo, mestreem Sociol ogia pela UniversidadedeBrasília(UnB), é diretor de Avaliação da Educação Básica do Instituto Nacional de Estudos e Pesquisas Educacionais (Daeb/lnep).

Frederico Neves Condeéanalista em Psicometria e consultor da Daeb/Inep.

Nildo Luzio, especialista em Políticas Públicas e Gestão Governamental, trabal ha atualmentena Daeb/Inep.

\section{Abstract Quality Index of Primary Education (IQE): proposal for discussion}

Thearticle displays the Quality Education Index (IQE), which was elaborated concerning three basic education indicators in the country: age-grade adequacy; school attendance, and the average scoring of the Brazilian states in the National System for Evaluation of Basic Education (Saeb). Therefore, the index reflects upon three components: school attendance, age-grade adequacy and the school performance measured by the proficiency obtained from the national evaluation; it basically represents the education results more than the inputs obtained from educational policies. The authors believe that a good education system must befundamentally evaluated by means of its capacity in providing school access to the population, by its school curriculum efficiency and by its capacity to add cognitive domains to students.

Keywords: evaluation; indicators; proficiency; attendance index; age-grade adequacy; school curriculum; N ational System for Evaluation; School Census; results indicators.

Recebido em 17 de junho de 2005 